\title{
Something Old, Something New: Ion Channel Blockers as Potential Anti-Tuberculosis Agents
}

\author{
Steven C. Mitini-Nkhoma ${ }^{1}$, Elizabeth T. Chimbayo ${ }^{1}$, David T. Mzinza ${ }^{1,2}$, \\ David V. Mhango ${ }^{1,2}$, Aaron P. Chirambo ${ }^{1}$, Christine Mandalasi ${ }^{1}$, Agness E. Lakudzala ${ }^{1}$, \\ Dumizulu L. Tembo ${ }^{1}$, Kondwani C. Jambo ${ }^{1,2}$ and Henry C. Mwandumba ${ }^{1,2 *}$ \\ ${ }^{1}$ Malawi-Liverpool-Wellcome Trust Clinical Research Programme, University of Malawi College of Medicine, Blantyre, Malawi, \\ 2 Department of Clinical Sciences, Liverpool School of Tropical Medicine, Liverpool, United Kingdom
}

OPEN ACCESS

Edited by: Bibhuti Mishra, Albany Medical College, United States

Reviewed by: Mohd Saqib, Albany Medical College, United States Kokila Kota

Ramapo College, United States

*Correspondence:

Henry C. Mwandumba Henry.Mwandumba@/stmed.ac.uk

Specialty section:

This article was submitted to Vaccines and Molecular Therapeutics, a section of the journal Frontiers in Immunology

Received: 08 February 2021 Accepted: 24 May 2021 Published: 24 June 2021

Citation: Mitini-Nkhoma SC, Chimbayo ET, Mzinza DT, Mhango DV, Chirambo AP, Mandalasi C, Lakudzala $A E$, Tembo DL, Jambo KC and Mwandumba HC (2021)

Something Old, Something New: Ion Channel Blockers as Potential Anti-Tuberculosis Agents.

Front. Immunol. 12:665785. doi: 10.3389/fimmu.2021.665785
Tuberculosis (TB) remains a challenging global health concern and claims more than a million lives every year. We lack an effective vaccine and understanding of what constitutes protective immunity against TB to inform rational vaccine design. Moreover, treatment of TB requires prolonged use of multi-drug regimens and is complicated by problems of compliance and drug resistance. While most Mycobacterium tuberculosis (Mtb) bacilli are quickly killed by the drugs, the prolonged course of treatment is required to clear persistent drug-tolerant subpopulations. Mtb's differential sensitivity to drugs is, at least in part, determined by the interaction between the bacilli and different host macrophage populations. Therefore, to design better treatment regimens for TB, we need to understand and modulate the heterogeneity and divergent responses that Mtb bacilli exhibit within macrophages. However, developing drugs de-novo is a long and expensive process. An alternative approach to expedite the development of new TB treatments is to repurpose existing drugs that were developed for other therapeutic purposes if they also possess anti-tuberculosis activity. There is growing interest in the use of immune modulators to supplement current anti-TB drugs by enhancing the host's antimycobacterial responses. Ion channel blocking agents are among the most promising of the host-directed therapeutics. Some ion channel blockers also interfere with the activity of mycobacterial efflux pumps. In this review, we discuss some of the ion channel blockers that have shown promise as potential anti-TB agents.

Keywords: mycobacterium, tuberculosis, host-directed therapies, ion channel blocker, efflux pump, drug-repurposing

\section{INTRODUCTION}

Tuberculosis (TB) is an airborne infection contracted by inhalation of droplet nuclei containing viable Mycobacterium tuberculosis (Mtb) that are released into the air by a person with active pulmonary TB. The disease has been a major cause of morbidity and mortality for several millennia (1). In 2019 alone, 10 million people developed active TB and 1.4 million of them died of the disease (2). 
Most of the TB cases in 2019 were in South-East Asia (44\%), Africa (25\%) and western Pacific (18\%) (2).

TB is challenging to treat even though there are now more than 20 first- and second-line anti-TB drugs in clinical use (3). Current anti-TB treatment regimens utilize combinations of no less than 3 drugs that must be taken for at least 6 months (3). The lengthy treatment duration and side effects of the drugs often lead to poor compliance with treatment, unfavorable outcomes and development of drug-resistant Mtb strains (4). In 2019, more than 0.5 million people developed multidrug-resistant (MDR) or rifampicin (RIF)-resistant (RR) TB worldwide (2). Treatment of drug-resistant TB requires longer and more complex drug regimens, and often causes more serious adverse effects than treatment of drug-susceptible TB (5). Current TB drugs target the pathogen and function by compromising the structural integrity or metabolic machinery of Mtb. In the last few years, host-directed therapy (HDT) targeting macrophages has emerged as a promising therapeutic strategy for both drugsusceptible TB and MDR-TB.

In the lung, alveolar macrophages (AMs) are among the most important innate defenses against Mtb. They phagocytose and eliminate bacteria through various pathways including phagosome maturation, autophagy and apoptosis. However, $\mathrm{Mtb}$ has evolved to survive inside macrophages by corrupting macrophage antimicrobial responses. HDTs for TB aim to rectify or circumvent the corrupted antimycobacterial responses.

Ion channel blockers are among the most promising potential HDTs for TB (Table 1). They are a diverse group of compounds that alter cell physiology by attenuating ion currents across cellular and subcellular membranes, and are most commonly used to treat noncommunicable diseases such as hypertension. Several Food and Drug Administration (FDA)-approved ion channel blocking agents have shown promise at both enhancing Mtb clearance by the immune system and attenuating inflammation in vitro and in animal models of TB (Figure 1). Additionally, some ion channel blocking agents have direct antimycobacterial activity. Here we review ion channel blocking agents that have demonstrated anti-tuberculosis activity in Mtb-infected macrophages and/or in animal models of TB.

\section{ION CHANNEL BLOCKERS WITH POTENTIAL AS ANTI-TUBERCULOSIS AGENTS}

\section{Calcium Channel Blockers}

Calcium ions $\left(\mathrm{Ca}^{2+}\right)$ act as second messengers in several signal transduction pathways (24). Calcium is more abundant in the extra cellular fluid (ECF) than in the cytosol (25). In the cell, most of the $\mathrm{Ca}^{2+}$ are sequestered in endoplasmic reticuli (ER) (25). Cell activation signals induce the flow of $\mathrm{Ca}^{2+}$ from the ER and ECF into the cytosol through channels such as inositol-1,4,5trisphosphate receptors $\left(\mathrm{IP}_{3} \mathrm{Rs}\right)$, ryanodine receptors (RyRs), voltage-gated calcium channels (VGCC) and calcium releaseactivated calcium (CRAC) channels.

$\mathrm{Ca}^{2+}$ signaling is important in antimycobacterial responses, including autophagy, phagosome maturation and apoptosis. In general, high cytosolic concentrations of $\mathrm{Ca}^{2+}$ promote phagosome maturation and acidification of mycobacteriacontaining phagosomes, necrosis and apoptosis; while cell autophagy can be both upregulated or downregulated by $\mathrm{Ca}^{2+}$ (26-28). Whether $\mathrm{Ca}^{2+}$ influx upregulates or downregulates autophagy depends on factors such as the biological context and the ion channel conducting the $\mathrm{Ca}^{2+}$ current. For example, $\mathrm{Ca}^{2+}$ currents through the ATP-gated cation channel $\mathrm{P} 2 \mathrm{X}_{7}$ receptor enhanced autophagy and intracellular killing of $M$. bovis-BCG in human macrophages, while currents through VGCCs inhibit autophagy $(26,28)$.

TABLE 1 | Progress towards clinical use of ion channel blockers as anti-tuberculosis agents.

\begin{tabular}{|c|c|c|}
\hline Year & Milestone & Refer \\
\hline 1990 & $\begin{array}{l}\text { Crowle and May demonstrated that chloroquine inhibits Mtb growth in macrophage cultures and potentiates streptomycin, pyrazinamide and } \\
\text { isoniazid }\end{array}$ & \\
\hline 1992 & Crowle and colleagues observed that chlorpromazine was more active against Mtb in macrophage cultures than in broth & \\
\hline 1993 & Klemens and colleagues reported that clofazimine was effective against an MDR-TB strain in mice & \\
\hline 1994 & $\begin{array}{l}\text { Gollapudi and colleagues demonstrated that verapamil improves accumulation of INH in Mtb-infected macrophages and promotes sensitivity of Mtb } \\
\text { to INH }\end{array}$ & \\
\hline 1996 & Grange and Snell demonstrated that ambroxol has antimycobacterial activity in macrophages & \\
\hline 2003 & Esiobu and Hoosein observed that sodium valproate inhibits growth of Mycobacterium smegmatis in broth & \\
\hline 2007 & Byrne and colleagues observed that ketoconazole was synergistic with rifampicin-isoniazid-pyrazinamide & \\
\hline 2010 & van Deun and colleagues successfully used clofazimine as part of a 9-month MDR-TB treatment regimen in a clinical trial & \\
\hline 2013 & Smolarz and colleagues demonstrated that resveratrol has antitubercular activity in broth & \\
\hline 2014 & Stanley and colleagues demonstrated that fluoxetine promotes autophagic control of Mtb in macrophages & \\
\hline 2015 & Schiebler and colleagues successfully reduced the bacteria burden in mice infected with MDR-TB using carbamazepine and valproic acid & \\
\hline 2016 & Machado and colleagues successfully used verapamil, thioridazine and chlorpromazine to decrease bacteria burden in Mtb-infected macrophages & \\
\hline 2016 & WHO conditionally recommended a short course MDR-TB treatment regimen containing clofazimine & \\
\hline 2018 & Choi and colleagues demonstrated that ambroxol promotes autophagy and potentiates rifampicin in murine models of TB & \\
\hline 2018 & $\begin{array}{l}\text { Rao and colleagues demonstrated that sodium valproate has antimycobacterial activity in broth and in macrophages in culture, and enhances } \\
\text { activity of rifampicin and isoniazid }\end{array}$ & \\
\hline 2019 & Roca and colleagues demonstrated that dantrolene inhibits necrotic death and promotes Mtb control in Mtb-infected macrophages & \\
\hline 2019 & Yang and colleagues demonstrated that resveratrol has antitubercular activity in mice & \\
\hline 2021 & Lee and colleagues observed that the use of calcium channel blockers was associated with a $32 \%$ decrease in the risk of active tuberculosis & \\
\hline
\end{tabular}




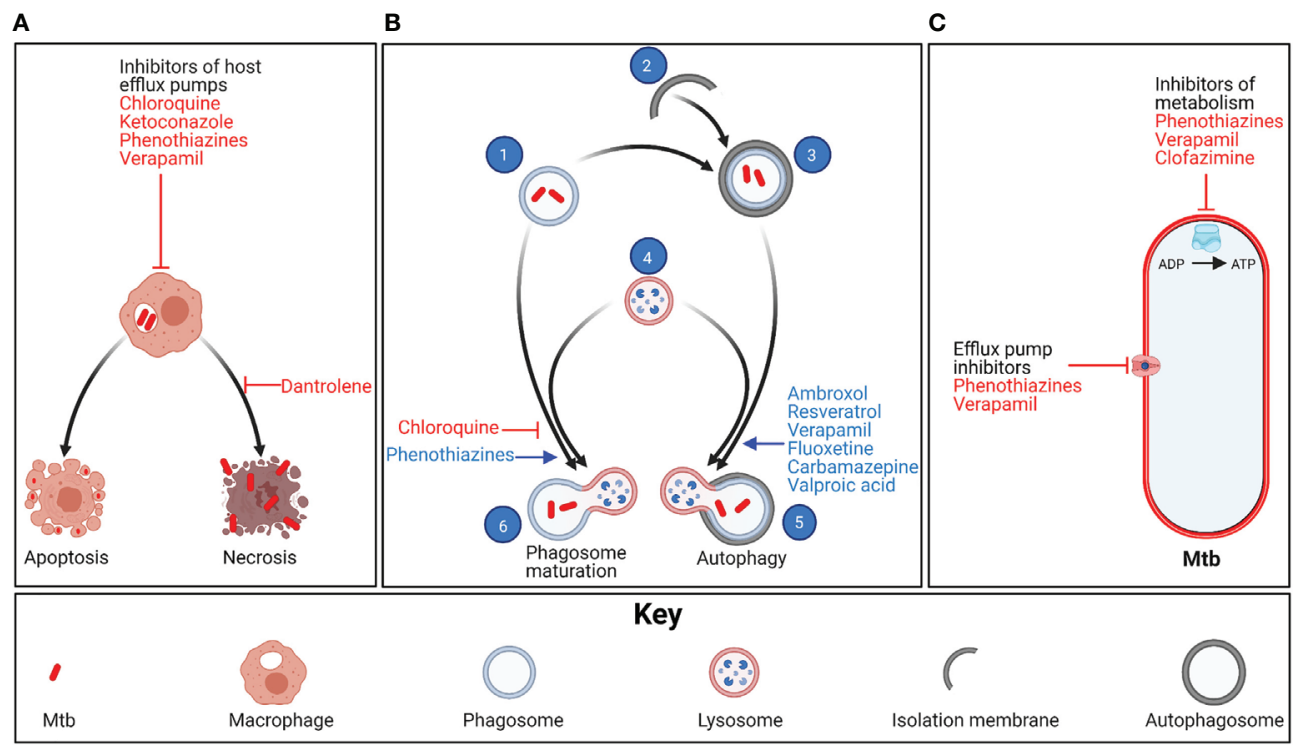

FIGURE 1 | Mechanism of action of ion channel blockers. (A) Chloroquine, ketoconazole, phenothiazines and verapamil inhibit eukaryotic efflux systems, allowing anti-TB drugs to achieve higher concentrations inside Mtb-infected host cells. Mtb promotes necrotic death of infected macrophages, leading to release of the bacteria into the extracellular space, where the bacteria continue to proliferate in the necrotic cells or infect new cells. In contrast, apoptotic cell death leads to enzymatic degradation of most of the bacteria. Dantrolene prevents necrotic death of Mtb-infected macrophages. (B) Phagocytosed Mtb (1) can also be eliminated through phagosome maturation and autophagy. In autophagy, isolation membranes (2) elongate and engulf phagosomes. The autophagosome-sequestered phagosomes (3) then fuse with lysosomes (4) to form autophagolysosomes (5), following which the lysosomal enzymes degrade the phagocytosed bacteria. Ambroxol, resveratrol, verapamil, fluoxetine, carbamazepine and valproic acid promote autophagy. In phagosome maturation, Mtb phagosomes fuse with lysosomes to form phagolysosomes (6). Phenothiazines promote acidification of phagolysosomes, thus enhancing activity of the lysosomal enzymes. In contrast, chloroquine inhibits phagosome maturation, thus preventing redox-induced Mtb drug tolerance, making the bacteria more susceptible to anti-TB drugs. (C) Phenothiazines and verapamil can also inhibit Mtb metabolism and efflux pump activity. Clofazimine, a second-line anti-TB agent, also inhibits Mtb metabolism. Created with BioRender.com.

A recent population-based analysis investigated whether the use of calcium channel blockers modifies the risk of active TB among patients with heart failure or cerebrovascular diseases in the clinical setting (23). The analysis included 8164 new active TB patients and 816,400 controls treated with or without calcium channel blockers compared with $\beta$ blockers or loop diuretics. Overall, the use of calcium channel blockers was associated with a $32 \%$ decrease in the risk of active TB [relative risk (RR), O.68 (95\% CI, 0.58-0.78)] after adjustment with disease risk score. Analysis of the effect of different types of calcium channel blockers revealed that use of dihydropyridine calcium channel blockers was associated with a lower risk of TB [RR, 0.63 (95\% CI, 0.53-0.79)] than nondihydropyridine calcium channel blockers [RR, 0.73 (95\% CI, 0.54-0.94)]. $\beta$-blockers or loop diuretics were not associated with lower risk of TB [RR, 0.99 (95\% CI, 0.83-1.12)] and [RR, 0.88, (95\% CI. 0.62-1.26)], respectively (23). This is the first large population-based study to confirm that calcium channel blockers modify and reduce the risk of active TB in humans. Therefore, modulating $\mathrm{Ca}^{2+}$ signaling using calcium channel blockers is an attractive host-directed therapeutic strategy for TB. Dantrolene, resveratrol and verapamil are the calcium channel blockers that have shown the most promise as potential anti-TB agents.

\section{Dantrolene}

Dantrolene is a RyR antagonist clinically approved for treatment of malignant hyperthermia. RyRs are intracellular $\mathrm{Ca}^{2+}$ channels that mediate the release of $\mathrm{Ca}^{2+}$ from the $\mathrm{ER}$ in response to elevated cytosolic $\mathrm{Ca}^{2+}$ levels (29). They are important in physiological and pathological processes, including necrosis and apoptosis. Apoptosis involves enzymatic degradation of intracellular contents including most of the phagocytosed bacteria, and their packaging into fragments called apoptotic bodies $(30,31)$. In contrast, necrosis involves swelling of organelles, loss of plasma membrane integrity and release of intracellular contents into the extracellular space (30). Mtb is able to continue growing inside necrotic macrophages, promoting lung inflammation and parenchymal injury (32). Mtb inhibits apoptotic cell death and promotes death of infected macrophages by necrosis (32). Roca et al. demonstrated the importance of ER-mitochondria signaling relay involving $\mathrm{RyR}$ and plasma membrane L-type $\mathrm{Ca}^{2+}$ channels for TNF-mediated necrosis of Mtb-infected macrophages in a zebrafish model of TB. Dantrolene reduced TNF-induced necrotic death of Mtb-infected macrophages by more than $50 \%$ by attenuating RyR activity and the surge in cytosolic $\mathrm{Ca}^{2+}$ that normally precedes necrosis, attesting to its potential as a HDT for TB (21). Inhibition of RyR activity 
with dantrolene has also been shown to promote autophagy (33), although this has not been demonstrated in Mtbinfected macrophages.

\section{Resveratrol}

Resveratrol (3, 5, 4'-trihydroxystilbene) is a natural polyphenol produced by plants including grapes and berries and widely used as a food supplement $(34,35)$. It interacts with and modulates the activity of at least 20 mammalian proteins including CRAC channels and VGCCs (36). Resveratrol attenuates Mtb-induced inflammatory responses and enhances elimination of $\mathrm{Mtb}$ in macrophages, at least in part by upregulating the expression of host sirtuin $1(37-39)$. Sirtuin 1 is a nicotinamide adenine dinucleotide $\left(\mathrm{NAD}^{+}\right)$-dependent deacetylase that deactivates ReLA, the p65 subunit of nuclear factor kappa B (NF- $\mathrm{KB})(40)$. $\mathrm{NF}-\kappa \mathrm{B}$ is a transcription factor important in the maturation of dendritic cells, M1 polarization of macrophages, differentiation of Th0 cells to the Th1 phenotype and expression of proinflammatory cytokines including IL-1, IL-8 and TNF- $\alpha$ (41, 42). Mtb down-regulates expression of host sirtuin 1 in monocytes/macrophages, in mouse models of $\mathrm{TB}$ and in $\mathrm{TB}$ patients with active disease, leading to overexpression of NF- $\kappa B$ (40). While NF- $\mathrm{KB}$ expression is generally associated with antiTB responses, NF- $\kappa B$ also inhibits apoptosis and autophagy, two of the pathways most effective at eliminating intracellular Mtb (43). Recently, Cheng et al. reported a log fold decrease in bacteria load after treating THP-1 cells infected with W148, an MDR-TB strain, with resveratrol for 3 days (40).

\section{Verapamil}

Verapamil is an L-type calcium channel (LTCC) blocker widely used for the treatment of hypertension, angina and abnormal heart rhythms. LTCCs are a subfamily of VGCCs, and are expressed on the plasma membrane of most cell types. $\mathrm{Ca}^{2+}$ currents through LTCCs inhibit release of ER calcium stores in macrophages, thus attenuating $\mathrm{Ca}^{2+}$-dependent signaling processes including macrophage activation (44). A previous study demonstrated that Mtb induces up-regulation of VGCCs in macrophages and dendritic cells to circumvent immune responses (44). Inhibiting LTCC currents in Mtb-infected macrophages with verapamil increases the concentration of $\mathrm{Ca}^{2+}$ in the cytosol, leading to upregulation of autophagy and Mtb killing (45-47).

The LTCC blockers verapamil and nifedipine also modulate iron metabolism by mobilizing iron from tissues, reducing intramacrophage iron concentration and enhancing urinary iron excretion $(48,49)$. Iron is a cofactor in numerous biochemical reactions and is an essential nutrient for growth, replication and pathogenicity of many intracellular pathogens including Mtb (50). Further, prolonged iron overload promoted insulin resistance in skeletal muscle cells in vitro and in vivo in a mouse model of iron overload by inhibiting mTORC1 activation on autolysosomes and interfering with autophagic lysosomal regeneration (51). Therefore, by limiting iron availability, LTCC blockers promote a key pathway to enhance host resistance and clearance of intracellular pathogens such as Mtb.
In addition to enhancing host mycobacterial responses, Verapamil is bactericidal to both replicating and nonreplicating Mtb in broth (52). It also inhibits both host and bacterial efflux pumps and is synergistic with RIF and isoniazid (INH) in broth, in macrophage cultures and in mouse models of TB (17, 52, 53). Gupta and colleagues reported that supplementing standard TB therapy with verapamil yielded an extra $1.15 \log$ CFU reduction in pulmonary bacterial load in a murine model of TB (54).

\section{Progress Towards Clinical Use of Calcium Channel Blockers as Anti-Tuberculosis Agents}

While evidence from in vitro and animal models of TB indicates that calcium channel blockers have anti-TB activity, there has been no progress in transitioning from pre-clinical findings to clinical practice. The use of dantrolene as an anti-TB agent could prove challenging due to its numerous adverse effects which include muscle weakness, sedation, visual disturbances and hallucinations (55). Compared to dantrolene, verapamil and resveratrol are generally well tolerated and would be the preferred compounds for repurposing as anti-TB agents. Therefore, there is need for human clinical trials to assess the efficacy of verapamil and resveratrol as clinically relevant adjunct HDTs for TB.

\section{Potassium Channel Blockers}

While $\mathrm{Ca}^{2+}$ directly modulate antimycobacterial responses, potassium $\left(\mathrm{K}^{+}\right)$, sodium $\left(\mathrm{Na}^{+}\right)$and chloride $\left(\mathrm{Cl}^{-}\right)$ions primarily modulate macrophage responses by modulating $\mathrm{Ca}^{2+}$ currents.

$\mathrm{K}^{+}$currents promote autophagy and other anti-TB responses in Mtb-infected macrophages (28). $\mathrm{K}^{+}$is more abundant in the cytosol than the ECF while $\mathrm{Ca}^{2+}, \mathrm{Na}^{+}$and $\mathrm{Cl}^{-}$are more abundant in the ECF than the cytosol. This creates an overall negative charge inside the cell relative to the ECF. The electrochemical gradient between the cytosol and ECF facilitates movement of calcium into the cytosol during macrophage activation. Outward $\mathrm{K}^{+}$currents help sustain $\mathrm{Ca}^{2+}$ entry and macrophage activation by preventing plasma membrane (PM) depolarization and maintaining an electrical gradient between the ECF and cytosol $(56,57)$. Several $\mathrm{K}^{+}$channel antagonists have shown promise as potential anti-TB drugs, but most appear to promote macrophage anti-TB responses by mechanisms remote from ion channel blockade. Such compounds include chloroquine, ketoconazole and clofazimine.

\section{Chloroquine}

Chloroquine has been in use as an antimalarial agent for over 5 decades. It also suppresses the activity of mammalian delayed rectifier $\mathrm{K}^{+}$channels (Kv1.3) in leukocytes and lymphocyte production of pro-inflammatory cytokines (58). Chloroquine has anti-inflammatory and immunomodulatory properties and is used to treat autoimmune diseases including rheumatoid arthritis and systemic lupus erythematosus. In addition, chloroquine has engendered interest as a potential HDT against several viral diseases. 
Mishra and colleagues observed a modest reduction in growth of intracellular Mtb following exposure to chloroquine alone, but a five-fold increase in the activity of INH when the two compounds were used together (59). The combination of chloroquine with INH eliminated $\mathrm{Mtb}$ within 8 weeks in a murine model of TB, while INH alone only reduced bacterial load by 2 logs during the same timeframe. Additionally, chloroquine eradicated drug-tolerant $\mathrm{Mtb}$, ameliorated lung pathology and reduced post-treatment $\mathrm{TB}$ relapse in in vivo mouse models of TB (59).

Chloroquine enhances the activity of INH through at least two divergent pathways. First, it inhibits phagosome acidification, thus reducing redox-induced Mtb drug tolerance (59). Second, chloroquine increases the intramacrophage concentration of INH by inhibiting the activity of $\mathrm{p}$ glycoprotein and breast cancer resistance protein-1 (BCRP-1) $(60,61)$. P-glycoprotein and BCRP-1 are mammalian efflux pumps that are overexpressed in $\mathrm{Mtb}$ infected macrophages, where they extrude anti-TB drugs into the ECF, thus protecting the intracellular bacteria from the antibiotics (62). Together, these studies suggest potential for repurposing chloroquine to shorten the duration of current $\mathrm{TB}$ treatment and to achieve relapse-free cure.

\section{Ketoconazole}

Ketoconazole is an azole antifungal used to treat cutaneous and systemic fungal infections. It kills fungi by inhibiting synthesis of ergosterol, an essential component of the fungal PM (63). Ketoconazole also inhibits the activity of voltage-gated potassium channels $\left(\mathrm{K}_{\mathrm{v}} 1.5, \mathrm{~K}_{\mathrm{v}} 11.1\right)$ and other mammalian proteins $(63,64)$.

The azole class of antifungals has been reported to possess anti-TB activity. Byrne and colleagues reported that ketoconazole inhibited growth of Mtb in broth (12). Furthermore, they observed a $3.42 \log$ CFU reduction in bacterial load in lungs of Mtb-infected mice that were treated with ketoconazole-RIF-INH-pyrazinamide (PZA), and a 3.08 log CFU reduction in mice that were treated with RIF-INH-PZA, indicating that ketoconazole is synergistic with current first-line anti-TB drugs (12). Ketoconazole enhances the activity of antiTB drugs, at least in part, by inhibiting pregnane $\mathrm{X}$ receptor (PXR), a promiscuous ligand-dependent transcriptional factor that is activated by steroid and xenobiotic agents $(65,66)$. PXR modulates expression of mammalian drug efflux and metabolism genes and reduces the efficacy of rifamycins against intracellular Mtb (67). The role of ketoconazole in the treatment of TB should be explored further.

\section{Clofazimine}

Clofazimine is a riminophenazine dye that is used as a first line agent in the treatment of leprosy, in combination with RIF and dapsone (68). It kills mycobacteria by disrupting multiple physiological processes, including respiration and $\mathrm{K}^{+}$transport across the PM (68). It was originally developed as an anti-TB drug more than five decades ago, but proved to be inferior to RIF and INH (68). The use of clofazimine to treat TB was revisited recently, and clofazimine has been listed as a second line anti-TB agent (2). The efficacy of various clofazimine-containing regiments against $\mathrm{MDR}-\mathrm{TB}$ is currently being assessed in the BEAT TB, endTB-Q and TB-PRACTECAL clinical trials (2). Furthermore, pre-clinical studies show that clofazimine could reduce the duration of treatment of drug-susceptible TB. Tyagi and colleagues successfully sterilized Mtb-infected mice with a 3month course of clofazimine-RIF-INH-PZA-ethambutol (EMB), but achieved a similar outcome with RIF-INH-PZA-EMB after treatment for 5 months (69). CLO-FAST, a phase 2 clinical trial is currently assessing the efficacy of a 3-month anti-TB regimen containing clofazimine and rifapentine against drug-susceptible TB (2).

In addition to its direct antimycobacterial activity, clofazimine has recently been shown to enhance host antimycobacterial responses by inhibiting mammalian Kv1.3 $\mathrm{K}^{+}$channels, which are highly expressed on effector memory $\mathrm{T}$ (Tem) lymphocytes $(70,71)$. Singh and colleagues demonstrated that inhibition of Kv1.3 channels on Tem cells by clofazimine during BCG vaccination in mice enhanced vaccine efficacy by promoting selective expansion of central memory $\mathrm{T}(\mathrm{Tcm})$ cells, a $\mathrm{T}$-cell subset that is associated with protective anti-TB responses. Mice that received clofazimine also exhibited significantly enhanced resistance against $\mathrm{TB}$ (71). These reports suggest $\mathrm{Kv} 1.3 \mathrm{~K}^{+}$channel blockade as a promising approach to enhance BCG vaccine efficacy in humans.

\section{Progress Towards Clinical Use of Potassium Channel Blockers as Anti-Tuberculosis Agents}

While clofazimine has now been adopted as an anti-TB agent, there has been no progress towards bringing ketoconazole and chloroquine into clinical use against TB. Azole antifungals such as ketoconazole and fluconazole are commonly used to treat concomitant candida or cryptococcal infections in HIV-infected TB patients but the impact of azole treatment on TB outcomes has not been assessed. Ketoconazole is generally well tolerated, but can cause serious adverse effects such as hepatotoxicity (72). Rifampicin, isoniazid and pyrazinamide can also cause druginduced hepatitis (73), therefore, concomitant use of these antiTB drugs with azole antifungals may increase the risk of hepatotoxicity. The safety of ketoconazole when used as adjunct treatment for $\mathrm{TB}$ requires further investigation.

\section{Sodium Channel Blockers}

There is paucity of data on the role of $\mathrm{Na}^{+}$channels in anti-TB responses. However, opening of $\mathrm{PM} \mathrm{Na}^{+}$channels leads to influx of $\mathrm{Na}^{+}$into the cytosol down its chemical gradient, thus reducing the electrical gradient between the ECF and cytosol. This reduces the driving force for $\mathrm{Ca}^{2+}$ entry. Most $\mathrm{PM} \mathrm{Na}^{+}$channels may therefore inhibit host antimycobacterial responses, and several $\mathrm{Na}^{+}$channel antagonists including ambroxol, carbamazepine and valproic acid promote host anti-TB responses $(16,19)$.

\section{Ambroxol}

Ambroxol is an inhibitor of voltage-gated sodium channel $\left(\mathrm{Na}_{\mathrm{v}}\right)$ 1.8 and is primarily used as a mucolytic agent (74). It is a potent inducer of autophagy and has garnered interest as a potential therapeutic agent to hasten degradation of misfolded proteins in 
proteinopathies including Parkinson's disease and primary alveolar proteinosis $(75,76)$. It has no direct antimycobacterial activity $(19,53)$, but it induces dose-dependent autophagic control of $\mathrm{Mtb}$ in vitro and in vivo and promotes mycobacterial killing in Mtb-infected primary mouse macrophages (19). Additionally, Choi and colleagues observed that ambroxol potentiated the antimycobacterial activity of rifampicin in a murine $\mathrm{TB}$ model, resulting in a three-fold decrease in bacterial load in mice treated with ambroxol and RIF relative to mice treated with RIF alone (19). Ambroxol warrants further evaluation as a HDT to augment and enhance the efficacy of current chemotherapy for TB in humans.

\section{Carbamazepine}

Carbamazepine is used to treat epilepsy, schizophrenia and bipolar disorder. It inhibits the activity of $\mathrm{Na}_{\mathrm{v}} 1.5$, thus indirectly inhibiting the uptake of inositol through $\mathrm{Na}^{+}$dependent inositol transporters on the PM (16). Inositol is a carbocyclic sugar upstream to biosynthesis of inositol-1,4,5trisphosphate $\left(\mathrm{IP}_{3}\right)$, a lipid second messenger that activates $\mathrm{IP}_{3} \mathrm{Rs}$ on ER. Blockade of inositol uptake by carbamazepine therefore reduces cytosolic levels of $\mathrm{IP}_{3}$, leading to decreased $\mathrm{Ca}^{2+}$ release from the ER and upregulation of autophagy (16). Treatment of MDR-TB-infected mice with carbamazepine for 30 days resulted in a ten-fold decrease in pulmonary bacterial load, improved lung pathology and stimulated adaptive immunity. This was achieved through induction of autophagic killing of intracellular Mtb, mediated by cellular depletion of inositol and independent of mTOR (16).

\section{Valproic acid}

Valproic acid is an inhibitor of $\mathrm{Na}_{\mathrm{v}} \mathrm{s}$, and is used to treat epilepsy, migraine and bipolar disorder $(77,78)$. It is active against Mtb in broth through mechanisms that have not been fully elucidated (20). Rao and colleagues observed a $1.5 \log$ CFU reduction in bacterial load following treatment of intracellular Mtb with valproic acid or INH, and a $2 \log \mathrm{CFU}$ reduction when the two drugs were used together (20). Like carbamazepine, valproic acid promotes autophagy by interfering with biosynthesis of $\mathrm{IP}_{3}(79)$. In addition, it inhibits host histone deacetylase 1 (HDAC1), a protein that is usually upregulated in Mtb-infected macrophages $(80,81)$. HDACs suppress gene expression by promoting chromatin packaging, thus making a segment of DNA inaccessible to the cellular transcription machinery (82). Upregulating HDAC1 in Mtb-infected macrophages reduces expression of IL-12 $\beta$, a cytokine important in the initiation of Th1 responses (80). Therefore, repurposing of carbamazepine and valproic acid as adjunct HDTs to enhance intracellular killing of Mtb by current anti-TB drugs should be explored as a treatment option for human TB.

\section{Progress Towards Clinical Use of Sodium Channel Blockers as Anti-Tuberculosis Agents}

The use of ambroxol, carbamazepine and valproic acid against TB has not been tested in a clinical trial setting. Carbamazepine and valproic acid are used widely as treatment for epilepsy in low- and middle-income countries where the burden of TB is high. However, the impact of concomitant use of sodium channel blockers and anti-TB treatment on TB outcomes has not been evaluated. Furthermore, both carbamazepine and valproic acid have been shown to cause hepatotoxicity in some individuals (83, 84 ), but there are no clinical trial data on the safety of carbamazepine and valproic when used in combination with existing anti-TB drugs.

\section{Other Ion Channel Blockers Fluoxetine}

Fluoxetine is a selective serotonin reuptake inhibitor (SSRI) and is primarily used as an anti-depressant. However, fluoxetine also has antiviral, antibacterial and immunomodulatory properties (85-87). In addition to inhibiting the uptake of serotonin into pre-synaptic neurons, fluoxetine modulates the activity of VGCCs, K2P, $\mathrm{Na}_{\mathrm{v}}$ s and 5-hydrotryptamine 3 (5-HT3) (88-90).

Schump and colleagues observed a $50 \%$ reduction in growth of intracellular Mtb following treatment with fluoxetine, even though it had limited activity against Mtb in broth (91). Several mechanisms for this have been described, including accumulation inside macrophages and induction of autophagy $(15,91)$. In another study, Stanley and colleagues demonstrated that fluoxetine promoted secretion of TNF- $\alpha$, induced autophagy and inhibited growth of intracellular Mtb by $75 \%$ in J774 cells (15). These observations merit evaluation of the antiTB activity of fluoxetine in clinical studies of human TB.

\section{Phenothiazines}

Phenothiazines are a large group of heterocyclic molecules most widely used as antipsychotics and antihistamines due to their ability to modulate dopamine signaling (92). Most phenothiazines bind to and modulate the activity of multiple mammalian proteins, including ligand-gated ion channels, ion pumps, G protein-coupled receptors and efflux pumps $(92,93)$.

The antimycobacterial properties of phenothiazines have been known for decades, but they were overshadowed by the current first line anti-TB compounds, to which they are inferior (7). However, the rise of MDR-TB has rekindled interest in the use of phenothiazines against Mtb. Most phenothiazines are active against extracellular Mtb at concentrations that cannot be achieved safely in vivo. However, they are generally active against intracellular Mtb at much lower concentrations (94). Some phenothiazines are concentrated by macrophages to at least 10 times their plasma concentrations, which may partly explain their potency against intracellular Mtb (94-96). Thioridazine, chlorpromazine, promethazine, methyldiazine and trifluoperazine are among the phenothiazines that have shown the most promise as potential anti-TB agents.

Thioridazine was once a popular drug for schizophrenia and psychosis but has largely been replaced by the newer generation of neuroleptics. It kills extracellular Mtb by disrupting ATP synthesis $(17,97)$. Machado and colleagues demonstrated that thioridazine promotes acidification of Mtb phagosomes, and reported an $88 \%$ increase in Mtb killing by thioridazine-treated macrophages (17). As thioridazine has multiple eukaryotic protein targets, the mechanism through which it promotes phagosome acidification has not been elucidated. However, one 
possible explanation is that it inhibits the efflux of ions from the phagolysosome, leading to indirect acidification (98).

In addition, thioridazine inhibits mycobacterial drug efflux systems, reduces resistance levels of different strains of MDR-TB to first and second-line anti-TB agents, and hastens clearance of drug-susceptible Mtb by first-line anti-TB agents $(17,95,99)$. Dutta and colleagues were able to sterilize lungs of mice infected with drug-susceptible Mtb with a 4 month course of thioridazine-RIF-INH-PZA, but achieved the same with RIFINH-PZA in 5 months (95).

\section{Progress Towards Clinical Use of Other Ion Channel Blockers as Anti-Tuberculosis Agents}

Fluoxetine and phenothiazines are currently not used as anti-TB drugs in clinical practice. However, thioridazine is relatively well tolerated, and has received more attention as a potential anti-TB agent than any other phenothiazine. There is need for clinical trials to determine the efficacy of thioridazine as part of anti-TB treatment regimens in humans.

\section{SUMMARY AND CONCLUDING REMARKS}

Ion channel blockers have the potential to contribute to the treatment of TB to reduce morbidity and mortality from the disease. Their ability to enhance the activity of first-line anti-TB drugs could help hasten clearance of Mtb from lungs of individuals with pulmonary $\mathrm{TB}$ disease, reduce transmission of infection, emergency of drug-resistant mutants and relapse rates. The ideal host-directed therapeutics for TB should potentiate the immune system's antimycobacterial defenses while preventing excessive inflammation and tissue injury. In addition to

\section{REFERENCES}

1. Hershkovitz I, Donoghue HD, Minnikin DE, Besra GS, Lee OYC, Gernaey AM, et al. Detection and Molecular Characterization of 9000-Year-Old Mycobacterium tuberculosis From a Neolithic Settlement in the Eastern Mediterranean. PLoS One (2008) 3(10):e3426. doi: 10.1371/journal.pone.0003426

2. World Health Organization. Global Tuberculosis Report 2020. Geneva: World Health Organisation (2020). Licence: CC BY-NC-SA 3.0 IGO.

3. Sotgiu G, Centis R, D’Ambrosio L, Migliori GB. Tuberculosis Treatment and Drug Regimens. Cold Spring Harb Perspect Med (2015) 5(5):a017822. doi: 10.1101/cshperspect.a017822

4. Mekonnen HS, Azagew AW. Non-Adherence to Anti-Tuberculosis Treatment, Reasons and Associated Factors Among TB Patients Attending at Gondar Town Health Centers, Northwest Ethiopia. BMC Res Notes (2018) 11(1):691. doi: 10.1186/s13104-018-3789-4

5. Yang TW, Park HO, Jang HN, Yang JH, Kim SH, Moon SH, et al. Side Effects Associated With the Treatment of Multidrug-Resistant Tuberculosis at a Tuberculosis Referral Hospital in South Korea: A Retrospective Study. Medicine (Baltimore) (2017) 96(28):e7482. doi: 10.1097/MD.0000000000007482

6. Crowle AJ, May MH. Inhibition of Tubercle Bacilli in Cultured Human Macrophages by Chloroquine Used Alone and in Combination With Streptomycin, Isoniazid, Pyrazinamide, and Two Metabolites of Vitamin D3. Antimicrob Agents Chemother (1990) 34(11):2217-22. doi: 10.1128/ AAC.34.11.2217

7. Crowle AJ, Douvas GS, May MH. Chlorpromazine: A Drug Potentially Useful for Treating Mycobacterial Infections. Chemotherapy (1992) 38(6):410-9. doi: $10.1159 / 000239036$ enhancing clearance of Mtb, ion channel blockers generally attenuate host inflammatory responses and may reduce tissue injury in TB patients. In the absence of a single agent that can eliminate $\mathrm{Mtb}$, combination therapy will remain the mainstay of TB treatment. While current drug combinations are designed to maximize clearance of Mtb by targeting the pathogen, ion channel blockers could enhance bacillary clearance by targeting both the pathogen and the host immune response. The reduction in the risk of active TB associated with the use of dihydropyridine calcium channel blockers is a cause for optimism and may pave the way for clinical trials of ion channel blockers as adjunct treatment for human TB.

\section{AUTHOR CONTRIBUTIONS}

SM-N wrote the manuscript with input from HM and DT. All authors contributed to the article and approved the submitted version.

\section{FUNDING}

$\mathrm{HM}$ and $\mathrm{KJ}$ are supported by African Research Leader Awards MR/P020526/1 and MR/T008822/1, respectively, jointly funded by the UK MRC and DFID under the MRC/DFID Concordant agreement. HCM is also supported by BMGF and NIH through grant numbers OPP1108452 and RO1AI155319, respectively. Wellcome Trust Core Funding Award number 206545/Z/17/Z supports the Malawi Liverpool Wellcome Trust Clinical Research Programme.

8. Klemens SP, DeStefano MS, Cynamon MH. Therapy of Multidrug-Resistant Tuberculosis: Lessons From Studies With Mice. Antimicrob Agents Chemother (1993) 37(11):2344-7. doi: 10.1128/AAC.37.11.2344

9. Gollapudi S, Reddy M, Gangadharam P, Tsuruo T, Gupta S. Mycobacterium Tuberculosis Induces Expression of P-glycoprotein in Promonocytic U1 Cells Chronically Infected With HIV Type 1. Biochem Biophys Res Commun (1994) 199(3):1181-7. doi: 10.1006/bbrc.1994.1355

10. Grange JM, Snell NJC. Activity of Bromhexine and Ambroxol, Semi-Synthetic Derivatives of Vasicine From the Indian Shrub Adhatoda Vasica, Against Mycobacterium tuberculosis In Vitro. J Ethnopharmacol (1996) 50(1):49-53. doi: 10.1016/0378-8741(95)01331-8

11. Esiobu N, Hoosein N. An Assessment of the In Vitro Antimicrobial Effects of Two Antiepileptic Drugs - Sodium Valproate and Phenytoin. Antonie van Leeuwenhoek (2003) 83(1):63-8. doi: 10.1023/A:1022992224594

12. Byrne ST, Denkin SM, Gu P, Nuermberger E, Zhang Y. Activity of Ketoconazole Against Mycobacterium tuberculosis In Vitro and in the Mouse Model. J Med Microbiol (2007) 56(Pt 8):1047-51. doi: 10.1099/ jmm.0.47058-0

13. Van Deun A, Maug AKJ, Salim MAH, Das PK, Sarker MR, Daru P, et al. Short, Highly Effective, and Inexpensive Standardized Treatment of Multidrug-Resistant Tuberculosis. Am J Respir Crit Care Med (2010) 182 (5):684-92. doi: 10.1164/rccm.201001-0077OC

14. Smolarz HD, Swatko-Ossor M, Ginalska G, Medynska E. Antimycobacterial Effect of Extract and its Components From Rheum Rhaponticum. J AOAC Int (2013) 96(1):155-60. doi: 10.5740/jaoacint.12-010

15. Stanley SA, Barczak AK, Silvis MR, Luo SS, Sogi K, Vokes M, et al. Identification of Host-Targeted Small Molecules That Restrict Intracellular 
Mycobacterium Tuberculosis Growth. PLoS Pathog (2014) 10(2):e1003946. doi: 10.1371/journal.ppat.1003946

16. Schiebler M, Brown K, Hegyi K, Newton SM, Renna M, Hepburn L, et al. Functional Drug Screening Reveals Anticonvulsants as Enhancers of mTORIndependent Autophagic Killing of Mycobacterium Tuberculosis Through Inositol Depletion. EMBO Mol Med (2015) 7(2):127-39. doi: 10.15252/ emmm.201404137

17. Machado D, Pires D, Perdigão J, Couto I, Portugal I, Martins M, et al. Ion Channel Blockers as Antimicrobial Agents, Efflux Inhibitors, and Enhancers of Macrophage Killing Activity Against Drug Resistant Mycobacterium tuberculosis. PLoS One (2016) 11(2):e0149326. doi: 10.1371/ journal.pone.0149326

18. World Health Organisation. WHO Treatment Guidelines for Drug-Resistant Tuberculosis : 2016 Update. Geneva: World Health Organisation (2016).

19. Choi SW, Gu Y, Peters RS, Salgame P, Ellner JJ, Timmins GS, et al. Ambroxol Induces Autophagy and Potentiates Rifampin Antimycobacterial Activity. Antimicrob Agents Chemother (2018) 62(9):e01019-18. doi: 10.1128/ aac.01019-18

20. Rao M, Valentini D, Zumla A, Maeurer M. Evaluation of the Efficacy of Valproic Acid and Suberoylanilide Hydroxamic Acid (Vorinostat) in Enhancing the Effects of First-Line Tuberculosis Drugs Against Intracellular Mycobacterium tuberculosis. Int J Infect Dis (2018) 69:78-84. doi: 10.1016/ j.ijid.2018.02.021

21. Roca FJ, Whitworth LJ, Redmond S, Jones AA, Ramakrishnan L. TNF Induces Pathogenic Programmed Macrophage Necrosis in Tuberculosis Through a Mitochondrial-Lysosomal-Endoplasmic Reticulum Circuit. Cell (2019) 178 (6):1344-1361.el1. doi: 10.1016/j.cell.2019.08.004

22. Yang H, Hu J, Chen YJ, Ge B. Role of Sirt1 in Innate Immune Mechanisms Against Mycobacterium Tuberculosis Via the Inhibition of TAK1 Activation. Arch Biochem Biophys (2019) 667:49-58. doi: 10.1016/j.abb.2019.04.006

23. Lee CC, Lee MTG, Hsu WT, Park JY, Porta L, Liu MA, et al. Use of Calcium Channel Blockers and Risk of Active Tuberculosis Disease: A PopulationBased Analysis. Hypertension (2021) 77(2):328-37. doi: 10.1161/ HYPERTENSIONAHA.120.15534

24. Newton AC, Bootman MD, Scott JD. Second Messengers. Cold Spring Harb Perspect Biol (2016) 8(8):a005926. doi: 10.1101/cshperspect.a005926

25. Clapham DE. Calcium Signaling. Cell (2007) 131(6):1047-58. doi: 10.1016/ j.cell.2007.11.028

26. Biswas D, Qureshi OS, Lee WY, Croudace JE, Mura M, Lammas DA. ATPInduced Autophagy Is Associated With Rapid Killing of Intracellular Mycobacteria Within Human Monocytes/Macrophages. BMC Immunol (2008) 9:35. doi: 10.1186/1471-2172-9-35

27. Kondratskyi A, Kondratska K, Skryma R, Prevarskaya N. Ion Channels in the Regulation of Apoptosis. Biochim Biophys Acta (2015) 1848(10 Pt B):2532-46. doi: 10.1016/j.bbamem.2014.10.030

28. Kondratskyi A, Kondratska K, Skryma R, Klionsky DJ, Prevarskaya N. Ion Channels in the Regulation of Autophagy. Autophagy (2018) 14(1):3-21. doi: 10.1080/15548627.2017.1384887

29. Hamilton SL. Ryanodine Receptors. Cell Calcium (2005) 38(3-4):253-60. doi: 10.1016/j.ceca.2005.06.037

30. Molloy A, Laochumroonvorapong P, Kaplan G. Apoptosis, But Not Necrosis, of Infected Monocytes Is Coupled With Killing of Intracellular Bacillus Calmette-Guérin. J Exp Med (1994) 180(4):1499-509. doi: 10.1084/ jem.180.4.1499

31. Kumar S, Birge RB. Efferocytosis. Curr Biol (2016) 26(13):R558-9. doi: 10.1016/j.cub.2016.01.059

32. Divangahi M, Behar SM, Remold H. Dying to Live: How the Death Modality of the Infected Macrophage Modulates Immunity to Tuberculosis. Adv Exp Med Biol (2013) 783:103-20. doi: 10.1007/978-1-4614-6111-1_6

33. Vervliet T. Ryanodine Receptors in Autophagy: Implications for Neurodegenerative Diseases? Front Cell Neurosci (2018) 12:89. doi: $10.3389 /$ fncel.2018.00089

34. Weiskirchen S, Weiskirchen R. Resveratrol: How Much Wine do You Have to Drink to Stay Healthy? Adv Nutr (2016) 7(4):706-18. doi: 10.3945/ an. 115.011627

35. Koushki M, Amiri-Dashatan N, Ahmadi N, Abbaszadeh HA, Rezaei-Tavirani M. Resveratrol: A Miraculous Natural Compound for Diseases Treatment. Food Sci Nutr (2018) 6(8):2473-90. doi: 10.1002/fsn3.855
36. McCalley AE, Kaja S, Payne AJ, Koulen P. Resveratrol and Calcium Signaling: Molecular Mechanisms and Clinical Relevance. Molecules (2014) 19(6):732740. doi: 10.3390/molecules 19067327

37. Coimbra ES, Santos JA, Lima LL, Machado PA, Campos DL, Pavan FR, et al. Synthesis, Antitubercular and Leishmanicidal Evaluation of Resveratrol Analogues. J Braz Chem Soc (2016) 27(12):2161-9. doi: 10.5935/01035053.20160107

38. Vestergaard $M$, Ingmer $H$. Antibacterial and Antifungal Properties of Resveratrol. Int J Antimicrob Agents (2019) 53(6):716-23. doi: 10.1016/ j.ijantimicag.2019.02.015

39. Zumla A, Rao M, Dodoo E, Maeurer M. Potential of Immunomodulatory Agents as Adjunct Host-Directed Therapies for Multidrug-Resistant Tuberculosis. BMC Med (2016) 14:89. doi: 10.1186/s12916-016-0635-1

40. Cheng CY, Gutierrez NM, Marzuki MB, Lu X, Foreman TW, Paleja B, et al. Host Sirtuin 1 Regulates Mycobacterial Immunopathogenesis and Represents a Therapeutic Target Against Tuberculosis. Sci Immunol (2017) 2(9):eaaj1789. doi: 10.1126/sciimmunol.aaj1789

41. Liu T, Zhang L, Joo D, Sun SC. NF-кB Signaling in Inflammation. Signal Transduct Target Ther (2017) 2:17023. doi: 10.1038/sigtrans.2017.23

42. Aronica MA, Mora AL, Mitchell DB, Finn PW, Johnson JE, Sheller JR, et al. Preferential Role for NF-kB/Rel Signaling in the Type 1 But Not Type2 T CellDependent Immune Response In Vivo. J Immunol (1999) 163(9):5116-24.

43. Bai X, Feldman NE, Chmura K, Ovrutsky AR, Su WL, Griffin L, et al. Inhibition of Nuclear Factor-Kappa B Activation Decreases Survival of Mycobacterium Tuberculosis in Human Macrophages. PLoS One (2013) 8 (4):e61925. doi: 10.1371/journal.pone.0061925

44. Gupta S, Salam N, Srivastava V, Singla R, Behera D, Khayyam KU, et al. Voltage Gated Calcium Channels Negatively Regulate Protective Immunity to Mycobacterium tuberculosis. PLoS One (2009) 4(4):e5305. doi: 10.1371/ journal.pone.0005305

45. Paik S, Kim JK, Chung C, Jo EK. Autophagy: A New Strategy for HostDirected Therapy of Tuberculosis. Virulence (2019) 10(1):448-59. doi: 10.1080/21505594.2018.1536598

46. Juárez E, Carranza C, Sánchez G, González M, Chávez J, Torres M, et al. Autophagy Inducing Drugs Contribute to Control Mycobacterium Tuberculosis Infection. Front Immunol. doi: 10.3389/conf.fimmu.2015.05.00160. Conference Abstract: IMMUNOCOLOMBIA2015 - 11th Congress of the Latin American Association of Immunology - 10o. Congreso de la Asociación Colombiana de Alergia, Asma e Inmunología.

47. Juárez E, Carranza C, Sánchez G, González M, Chávez J, Sarabia C, et al. Loperamide Restricts Intracellular Growth of Mycobacterium Tuberculosis in Lung Macrophages. Am J Respir Cell Mol Biol (2016) 55(6):837-47. doi: $10.1165 / \mathrm{rcmb} .2015-0383 \mathrm{OC}$

48. Shan HL, Wang Y, Wu JW, Hang PZ, Li X, Sun LH, et al. Verapamil Reverses Cardiac Iron Overload in Streptozocin-Induced Diabetic Rats. Naunyn Schmiedebergs Arch Pharmacol (2013) 386(7):645-50. doi: 10.1007/s00210013-0863-2

49. Ludwiczek S, Theurl I, Muckenthaler MU, Jakab M, Mair SM, Theurl M, et al. Ca2+ Channel Blockers Reverse Iron Overload by a New Mechanism Via Divalent Metal Transporter-1. Nat Med (2007) 13(4):448-54. doi: 10.1038/ nm1542

50. Zhang L, Hendrickson RC, Meikle V, Lefkowitz EJ, Ioerger TR, Nierderweis M. Comprehensive Analysis of Iron Utilization by Mycobacterium Tuberculosis. PLoS Pathog (2020) 16(2):e1008337. doi: 10.1371/ journal.ppat.1008337

51. Jahng JWS, Alsaadi RM, Palanivel R, Song E, Hipolito VEB, Sung HK, et al. Iron Overload Inhibits Late Stage Autophagic Flux Leading to Insulin Resistance. EMBO Rep (2019) 20(10):e47911. doi: 10.15252/embr.201947911

52. Chen C, Gardete S, Jansen RS, Shetty A, Dick T, Rhee KY, et al. Verapamil Targets Membrane Energetics in Mycobacterium tuberculosis. Antimicrob Agents Chemother (2018) 62(5):e02107. doi: 10.1128/AAC.02107-17

53. Mitini-Nkhoma SC, Fernando N, Ishaka GKD, Handunnetti SM, Pathirana SL. Ion Transport Modulators as Antimycobacterial Agents. Tuberc Res Treat (2020) 2020:1-7. doi: 10.1155/2020/3767915

54. Gupta S, Tyagi S, Almeida DV, Maiga MC, Ammerman NC, Bishai WR. Acceleration of Tuberculosis Treatment by Adjunctive Therapy With Verapamil as an Efflux Inhibitor. Am J Respir Crit Care Med (2013) 188 (5):600-7. doi: 10.1164/rccm.201304-0650OC 
55. Wedel DJ, Quinlan JG, Iaizzo PA. Clinical Effects of Intravenously Administered Dantrolene. Mayo Clin Proc (1995) 70(3):241-6. doi: 10. 4065/70.3.241

56. Lewis RS, Cahalan MD. Potassium and Calcium Channels in Lymphocytes. Annu Rev Immunol (1995) 13:623-53. doi: 10.1146/annurev.iy.13.040 195.003203

57. Hou P, Zhang R, Liu Y, Feng J, Wang W, Wu Y, et al. Physiological Role of Kv1.3 Channel in T Lymphocyte Cell Investigated Quantitatively by Kinetic Modeling. PLoS One (2014) 9(3):e89975. doi: 10.1371/journal.pone.0089975

58. Kazama I. Targeting Lymphocyte Kv1.3-Channels to Suppress Cytokine Storm in Severe COVID-19: Can it be a Novel Therapeutic Strategy? Drug Discov Ther (2020) 14(3):143-4. doi: 10.5582/ddt.2020.03046

59. Mishra R, Kohli S, Malhotra N, Bandyopadhyay P, Mehta M, Munshi M, et al. Targeting Redox Heterogeneity to Counteract Drug Tolerance in Replicating Mycobacterium Tuberculosis. Sci Transl Med (2019) 11(518):eaaw6635. doi: $10.1126 /$ scitranslmed.aaw6635

60. Matt U, Müller R, Müller D, Stenziger A, Zinkernagel A, Seelig A, et al. Chloroquine as a Potential Adjunctive Therapy in Tuberculosis. Eur Respir J (2014) 44(Suppl 58):1896.

61. Matt U, Selchow P, Dal Molin M, Strommer S, Sharif O, Schilcher K, et al. Chloroquine Enhances the Antimycobacterial Activity of Isoniazid and Pyrazinamide by Reversing Inflammation-Induced Macrophage Efflux. Int $J$ Antimicrob Agents (2017) 50(1):55-62. doi: 10.1016/j.ijantimicag.2017.02.022

62. te Brake LHM, de Knegt GJ, de Steenwinkel JE, van Dam TJP, Burger DM, Russel FGM, et al. The Role of Efflux Pumps in Tuberculosis Treatment and Their Promise as a Target in Drug Development: Unraveling the Black Box. Annu Rev Pharmacol Toxicol (2018) 58:271-91. doi: 10.1146/annurevpharmtox-010617-052438

63. Zonios DI, Bennett JE. Update on Azole Antifungals. Semin Respir Crit Care Med (2008) 29(2):198-210. doi: 10.1055/s-2008-1063858

64. Dumaine R, Roy ML, Brown AM. Blockade of HERG and Kv1.5 by Ketoconazole. J Pharmacol Exp Ther (1998) 286(2):727-35.

65. Pavek P. Pregnane X Receptor (PXR)-Mediated Gene Repression and CrossTalk of PXR With Other Nuclear Receptors Via Coactivator Interactions. Front Pharmacol (2016) 7:456. doi: 10.3389/fphar.2016.00456

66. Bhagyaraj E, Tiwari D, Ahuja N, Nanduri R, Saini A, Kalra R, et al. A Human Xenobiotic Nuclear Receptor Contributes to Nonresponsiveness of Mycobacterium tuberculosis to the Antituberculosis Drug Rifampicin. J Biol Chem (2018) 293(10):3747-57. doi: 10.1074/jbc.M117.818377

67. Shehu AI, Li G, Xie W, Ma X. The Pregnane X Receptor in Tuberculosis Therapeutics. Expert Opin Drug Metab Toxicol (2016) 12(1):21-30. doi: $10.1517 / 17425255.2016 .1121381$

68. Cholo MC, Steel HC, Fourie PB, Germishuizen WA, Anderson R. Clofazimine: Current Status and Future Prospects. J Antimicrob Chemother (2012) 67(2):290-8. doi: 10.1093/jac/dkr444

69. Tyagi S, Ammerman NC, Li SY, Adamson J, Converse PJ, Swanson RV, et al. Clofazimine Shortens the Duration of the First-Line Treatment Regimen for Experimental Chemotherapy of Tuberculosis. Proc Natl Acad Sci U S A (2015) 112(3):869-74. doi: 10.1073/pnas.1416951112

70. Ren YR, Pan F, Parvez S, Fleig A, Chong CR, Xu J, et al. Clofazimine Inhibits Human Kv1.3 Potassium Channel by Perturbing Calcium Oscillation in T Lymphocytes. PLoS One (2008) 3(12):e4009. doi: 10.1371/journal. pone.0004009

71. Singh DK, Dwivedi VP, Ranganathan A, Bishai WR, Van Kaer L, Das G. Blockade of the Kv1.3 K+ Channel Enhances BCG Vaccine Efficacy by Expanding Central Memory T Lymphocytes. J Infect Dis (2016) 214 (9):1456-64. doi: 10.1093/infdis/jiw395

72. Heiberg JK, Svejgaard E. Toxic Hepatitis During Ketoconazole Treatment. $\mathrm{Br}$ Med J (Clin Res Ed) (1981) 283(6295):825-6. doi: 10.1136/bmj.283.6295.825

73. Askgaard DS, Wilcke T, Dossing M. Hepatotoxicity Caused by the Combined Action of Isoniazid and Rifampicin. Thorax (1995) 50(2):213-4. doi: 10.1136/ thx.50.2.213

74. Leffler A, Reckzeh J, Nau C. Block of Sensory Neuronal Na+ Channels by the Secreolytic Ambroxol Is Associated With an Interaction With Local Anesthetic Binding Sites. Eur J Pharmacol (2010) 630(1-3):19-28. doi: 10.1016/j.ejphar.2009.12.027

75. Oda N, Tamai K, Suzuki Y, Yoshimatsu H, Matsuoka H, Matsumoto Y, et al. Marked Improvement in Autoimmune Pulmonary Alveolar Proteinosis With
Severe Hypoxemia in a Patient Treated With Ambroxol: A Case Report. J Med Case Rep (2015) 9:100. doi: 10.1186/s13256-015-0588-6

76. Mullin S, Smith L, Lee K, D'Souza G, Woodgate P, Elflein J, et al. Ambroxol for the Treatment of Patients With Parkinson Disease With and Without Glucocerebrosidase Gene Mutations: A Nonrandomized, Noncontrolled Trial. JAMA Neurol (2020) 77(4):427-34. doi: 10.1001/jamaneurol.2019.4611

77. Ghodke-Puranik Y, Thorn CF, Lamba JK, Leeder JS, Song W, Birnbaum AK, et al. Valproic Acid Pathway: Pharmacokinetics and Pharmacodynamics. Pharmacogenet Genomics (2013) 23(4):236-41. doi: 10.1097/FPC.0b013e $32835 \mathrm{ea} 0 \mathrm{~b} 2$

78. Zanatta G, Sula A, Miles AJ, Ng LCT, Torella R, Pryde DC, et al. Valproic Acid Interactions With the NavMs Voltage-Gated Sodium Channel. Proc Natl Acad Sci U S A (2019) 116(52):26549-54. doi: 10.1073/pnas. 1909696116

79. Ji MM, Wang L, Zhan Q, Xue W, Zhao Y, Zhao X, et al. Induction of Autophagy by Valproic Acid Enhanced Lymphoma Cell Chemosensitivity Through HDAC-Independent and IP3-Mediated PRKAA Activation. Autophagy (2015) 11(12):2160-71. doi: 10.1080/15548627.2015.1082024

80. Chandran A, Antony C, Jose L, Mundayoor S, Natarajan K, Kumar RA. Mycobacterium tuberculosis Infection Induces HDAC1-Mediated Suppression of IL-12B Gene Expression in Macrophages. Front Cell Infect Microbiol (2015) 5:90. doi: 10.3389/fcimb.2015.00090

81. Soria-Castro R, Schcolnik-Cabrera A, Rodríguez-López G, Campillo-Navarro M, Puebla-Osorio N, Estrada-Parra S, et al. Exploring the Drug Repurposing Versatility of Valproic Acid as a Multifunctional Regulator of Innate and Adaptive Immune Cells. J Immunol Res (2019) 2019:9678098. doi: 10.1155/ 2019/9678098

82. Gatla HR, Muniraj N, Thevkar P, Yavvari S, Sukhavasi S, Makena MR. Regulation of Chemokines and Cytokines by Histone Deacetylases and an Update on Histone Decetylase Inhibitors in Human Diseases. Int J Mol Sci (2019) 20(5):1110. doi: 10.3390/ijms20051110

83. Kalapos MP. Carbamazepine-Provoked Hepatotoxicity and Possible Aetiopathological Role of Glutathione in the Events: Retrospective Review of Old Data and Call for New Investigation. Adverse Drug React Toxicol Rev (2002) 21(3):123-41. doi: 10.1007/BF03256188

84. Gayam V, Mandal AK, Khalid M, Shrestha B, Garlapati P, Khalid M. Valproic Acid Induced Acute Liver Injury Resulting in Hepatic Encephalopathy- A Case Report and Literature Review. J Community Hosp Intern Med Perspect (2018) 8(5):311-4. doi: 10.1080/20009666.2018.1514933

85. Di Rosso ME, Palumbo ML, Genaro AM. Immunomodulatory Effects of Fluoxetine: A New Potential Pharmacological Action for a Classic Antidepressant Drug? Pharmacol Res (2016) 109:101-7. doi: 10.1016/ j.phrs.2015.11.021

86. Karine de Sousa A, Rocha JE, Gonçalves de Souza T, Sampaio de Freitas T, Ribeiro-Filho J, Melo Coutinho HD. New Roles of Fluoxetine in Pharmacology: Antibacterial Effect and Modulation of Antibiotic Activity. Microb Pathog (2018) 123:368-71. doi: 10.1016/j.micpath.2018.07.040

87. Bauer L, Manganaro R, Zonsics B, Strating JRPM, El Kazzi P, Lorenzo Lopez $\mathrm{M}$, et al. Fluoxetine Inhibits Enterovirus Replication by Targeting the Viral 2C Protein in a Stereospecific Manner. ACS Infect Dis (2019) 5(9):1609-23. doi: 10.1021/acsinfecdis.9b00179

88. Poulin H, Bruhova I, Timour Q, Theriault O, Beaulieu JM, Frassati D, et al. Fluoxetine Blocks Nav1.5 Channels Via a Mechanism Similar to That of Class 1 Antiarrhythmics. Mol Pharmacol (2014) 86(4):378-89. doi: 10.1124/ mol.114.093104

89. Bétry C, Etiévant A, Oosterhof C, Ebert B, Sanchez C, Haddjeri N. Role of 5HT3 Receptors in the Antidepressant Response. Pharmaceuticals (2011) 4 (4):603-29. doi: 10.3390/ph4040603

90. Dong YY, Pike ACW, Mackenzie A, McClenaghan C, Aryal P, Dong L, et al. K2P Channel Gating Mechanisms Revealed by Structures of TREK-2 and a Complex With Prozac. Science (2015) 347(6227):1256-9. doi: 10.1126/ science. 1261512

91. Schump MD, Fox DM, Bertozzi CR, Riley LW. Subcellular Partitioning and Intramacrophage Selectivity of Antimicrobial Compounds Against Mycobacterium Tuberculosis. Antimicrob Agents Chemother (2017) 61(3): e01639-16. doi: 10.1128/AAC.01639-16

92. Jaszczyszyn A, Gạsiorowski K, Świątek P, Malinka W, Cieślik-Boczula K, Petrus J, et al. Chemical Structure of Phenothiazines and Their Biological 
Activity. Pharmacol Rep (2012) 64(1):16-23. doi: 10.1016/S1734-1140(12) 70726-0

93. Wu CH, Bai LY, Tsai MH, Chu PC, Chiu CF, Chen MY, et al. Pharmacological Exploitation of the Phenothiazine Antipsychotics to Develop Novel Antitumor Agents-A Drug Repurposing Strategy. Sci Rep (2016) 6:27540. doi: 10.1038/srep27540

94. Viveiros M, Amaral L. Enhancement of Antibiotic Activity Against Poly-Drug Resistant Mycobacterium tuberculosis by Phenothiazines. Int J Antimicrob Agents (2001) 17(3):225-8. doi: 10.1016/S0924-8579(00)00343-5

95. Dutta NK, Pinn ML, Karakousis PC. Sterilizing Activity of Thioridazine in Combination With the First-Line Regimen Against Acute Murine Tuberculosis. Antimicrob Agents Chemother (2014) 58(9):5567-9. doi: 10.1128/AAC.03408-14

96. Jiang C, Yang W, Wang C, Qin W, Ming J, Zhang M, et al. Methylene BlueMediated Photodynamic Therapy Induces Macrophage Apoptosis Via ROS and Reduces Bone Resorption in Periodontitis. Oxid Med Cell Longev (2019) 2019:1529520. doi: 10.1155/2019/1529520

97. Amaral L, Kristiansen JE, Abebe LS, Millett W. Inhibition of the Respiration of Multi-Drug Resistant Clinical Isolates of Mycobacterium Tuberculosis by Thioridazine: Potential Use for Initial Therapy of Freshly Diagnosed Tuberculosis. J Antimicrob Chemother (1996) 38(6):1049-53. doi: 10.1093/ jac/38.6.1049
98. Amaral L, Viveiros M. Thioridazine: A Non-Antibiotic Drug Highly Effective, in Combination With First Line Anti-Tuberculosis Drugs, Against Any Form of Antibiotic Resistance of Mycobacterium tuberculosis Due to its MultiMechanisms of Action. Antibiotics (2017) 6(1):3. doi: 10.3390/ antibiotics6010003

99. van Soolingen D, Hernandez-Pando R, Orozco H, Aguilar D, Magis-Escurra C, Amaral L, et al. The Antipsychotic Thioridazine Shows Promising Therapeutic Activity in a Mouse Model of Multidrug-Resistant Tuberculosis. PLoS One (2010) 5(9):e12640. doi: 10.1371/journal. pone. 0012640

Conflict of Interest: The authors declare that the manuscript was written in the absence of any commercial or financial relationships that could be construed as a potential conflict of interest.

Copyright (๑ 2021 Mitini-Nkhoma, Chimbayo, Mzinza, Mhango, Chirambo, Mandalasi, Lakudzala, Tembo, Jambo and Mwandumba. This is an open-access article distributed under the terms of the Creative Commons Attribution License (CC BY). The use, distribution or reproduction in other forums is permitted, provided the original author(s) and the copyright owner(s) are credited and that the original publication in this journal is cited, in accordance with accepted academic practice. No use, distribution or reproduction is permitted which does not comply with these terms. 